\title{
A phylogenetic and biogeographic perspective on the evolution of poeciliid fishes
}

\author{
Tomas Hrbek ${ }^{\mathrm{a}, \mathrm{b}, 1}$, Jens Seckinger ${ }^{\mathrm{a}}$, Axel Meyer ${ }^{\mathrm{a}, *}$ \\ ${ }^{\text {a }}$ Lehrstuhl für Zoologie und Evolutionsbiologie, Department of Biology, University of Konstanz, 78457 Konstanz, Germany \\ ${ }^{\mathrm{b}}$ Department of Anatomy and Neurobiology, Washington University School of Medicine, Campus Box 8108, St. Louis, MO 63110, USA
}

Received 1 June 2006; accepted 11 June 2006

Available online 17 June 2006

\begin{abstract}
Phylogenetic relationships of members of the subfamily Poeciliinae (Cyprinodontiformes) are investigated to test alternate hypotheses of diversification resulting from the assembly of the Central America and the Caribbean from the Cretaceous period onwards. We use 4333 aligned base pairs of mitochondrial DNA and 1549 aligned base pairs of nuclear DNA from 55 samples representing 48 ingroup and seven outgroup species to test this hypothesis. Mitochondrial genes analyzed include those encoding the $12 \mathrm{~S}$ and $16 \mathrm{~S}$ ribosomal RNAs; transfer RNAs coding for valine, leucine, isoleucine, glutamine, methionine, tryptophan, alanine, asparagine, cysteine and tyrosine; and complete cytochrome $b$ and NADH dehydrogenase subunit I and II; nuclear gene analyzed included the third exon of the recombination activation gene 1 (RAG1). Analyses of combined mtDNA and nuclear DNA data sets result in a well-supported phylogenetic hypothesis. This hypothesis is in conflict with the classical taxonomic assignment of genera into tribes and phylogenetic hypotheses based on the taxonomy; however, the molecular hypothesis defines nine clades that are geographically restricted and consistent with the geological evolution of Central America and the Caribbean. Our analyses support multiple colonization events of Middle America followed by a mix of vicariance and dispersal events.
\end{abstract}

(C) 2006 Elsevier Inc. All rights reserved.

Keywords: Biogeography; Molecular phylogeny; Rapid diversification; Systematics; Central America; mtDNA; nDNA

\section{Introduction}

The family Poeciliidae (Rosen and Bailey, 1963), or the subfamily Poeciliinae, as classified by Parenti (1981), is a widespread and diverse group of small-sized fishes that includes 22-29 genera and more than 200 species (Lucinda, 2003). Members of the subfamily are endemic to the New World with majority of the species occurring in Mexico, Central America and the Antilles. They are one of four groups of cyprinodontiform fishes that evolved internal fertilization, and one of three groups that evolved live-bearing (Parenti, 1981; Meyer and Lydeard, 1993). The pattern of

\footnotetext{
* Corresponding author. Fax: +49 7531883018.

E-mail address: axel.meyer@uni-konstanz.de (A. Meyer).

${ }^{1}$ Present address: Department of Biology, University of Puerto Rico, Rio Piedras, San Juan, PR 00931, Puerto Rico.
}

internal fertilization and live-bearing is found in all members of the family with the exception of Tomeurus gracilis that is hypothesized to be the sister taxon of all other poeciliid species (Parenti and Rauchenberger, 1989; Lucinda and Reis, 2005); however, Ghedotti (2000) found it to be deeply nested within the Poeciliinae. Tomeurus gracilis has internal fertilization, but is an obligatory egg-layer that retains eggs in the oviduct for several days after fertilization (Rosen, 1964). Within the live-bearing species, there are different levels of post-fertilization maternal provisioning of the unborn young, and some species possess multiple simultaneous gestations, a condition referred to as 'superfetation' (Thibault and Schultz, 1978; Reznick and Miles, 1989). Perhaps the most interesting, and developmentally most complex, is the evolution of post-fertilization maternal provisioning via placenta-like structures (Turner, 1940). These placenta-like structures termed 'folicular 
pseudo-placentas' by Turner (1940) represent a modified pericardial membrane used in maternal-fetal nutrient transport.

Poeciliids are a conspicuous faunal component of Meso America accounting for approximately $35 \%$ of its secondary freshwater fish fauna (Miller, 1966), and thus have played a prominent role in studies of vicariance biogeography of Central America and the Caribbean. Rosen (1975) published a seminal paper on the zoogeography of this region, proposing a plate tectonic-based vicariance model. His model hypothesized that the eastward drift of a protoAntillean archipelago from its position between Nuclear Central America and South America in the late Cretaceous to early Paleocene fragmented the widespread taxa found throughout the region into three components: South America, Nuclear Central America, and the West Indies. Later, orogenic processes and changes in the climate led to the isolation of Nuclear Central America and North America. In the Pliocene, South Central America joined Nuclear Central America and South America and allowed for the limited dispersal of taxa in both directions.

Rosen's (1975) hypothesis was compatible with that of Savage (1966) who examined distributional, geologic, climatological and faunal affinities of the herpetofauna of the region and provided evidence that Central America and South America were connected in the Cretaceous to Paleocene, but fragmented subsequently. The Central and South American faunas were not fully connected until the formation of Lower Central America in the late Pliocene. This hypothesis was reexamined and reiterated by Savage (1982) in a form of a vicariance model for the region. The hypothesis of a Cretaceous to Paleocene connection of Central and South America was also supported by Bussing (1976) based on revised fish provinces of Miller (1966). Bussing (1976) considered all poeciliids to be members of an 'Old Southern Element', and thus the primitive stock was believed to be a widespread ancestral taxon found in both Central America and South America. The two areas separated in the post-Paleocene allowing for the independent evolution of the isolated lineages. Once the two areas rejoined in the late Pliocene, members of the 'New Southern Element' (e.g. Ostariophysan fishes) dispersed into Central America.

Myers (1966), on the other hand, thought a late Cretaceous-Paleocene connection was unlikely, because it would have allowed Ostariophysan fishes to disperse to Central America as well, and poeciliids would not be as predominant as they now are in Central America due to the competitive superiority of Ostariophysan fishes. A later publication of Savage (1974) based on mammalian distributional patterns also found no strong evidence in favor of a Cretaceous-Paleocene connection of Central and South America. In addition, although Myers (1966) admitted that it was not easy to assign the origin of poeciliids to either Central or South America, he proposed that the poeciliids main evolutionary center was in Central America, because all of the main tribes except Tomeurini were known from Central America. He assumed that the other four South American genera in the tribe Cnesterodontini were derived from an as yet undescribed genus (Scolichthys; Rosen, 1967), which Rosen suggested "resembled" members of the tribe Cnesterodontini (Rosen later placed the genus in its own tribe, Scolichthyini).

More recently a general model of geological evolution of the Carribean basin and resulting biogeographical implications has been proposed by Iturralde-Vinent and MacPhee (1999). This model proposes that a late Cretaceous connection existed between North American and South America via Central America, but that Greater Antilles did not become permanently emerged until the Eocene-Oligocene transition during which time they also were connected to northern South America via the Aves ridge. Therefore Antillean taxa should have South American affinities and be no older than the late Eocene.

A summary of the three main models is as follows:

(1) Rosen's (1975) model predicts a trichotomy of Cretaceous age among South America, Caribbean and Nuclear Central America. Nuclear Central America is composed of Mexico and North American components which separate after the Cretaceous. Implicitly, Lower Central America is colonized from Nuclear Central America. Following the Pliocene closing of the Isthmus of Panama, limited exchange occurs through Lower Central America between Nuclear Central America and South America. No origin of poeciliids is proposed, they are a wide-spread group before the Cretaceous fragmentation.

(2) Myers's (1966) model predicts no age for poeciliids, but does put forth the hypothesis that South American poeciliids are derived from Central American poeciliids, and that poeciliids have dispersed to South America after the closing of Isthmus of Panama during the late Pliocene. Thus South American poeciliids should be phylogenetically nested within Central American poeciliids, and no older than the late Pliocene.

(3) Iturralde-Vinent and MacPhee's (1999) model predicts a basal Cretaceous sister taxon relationship between South American and Middle American taxa, an Eocene-Oligocene sister taxon relationship between Great Antillean (Caribbean) and South American taxa with the caveat that Caribbean taxa are no older than the late Eocene. Following the closure of the Isthmus of Panama in the late Pliocene, exchange of taxa in both directions is possible between Middle and North America.

These biogeographical models differ in three not necessarily mutually exclusive points: (1) whether or not a Cretaceous and a Pliocene, or only a Pliocene connection between Central and South America existed: Rosen, and Iturralde-Vinent and MacPhee vs. Myers; (2) whether poeciliids were a wide-spread group in the Central and South America region, or if they were restricted to Central America, and only subsequent to the formation of the 
Isthmus of Panama 3.5-3 million years ago (Keigwin, 1982; Coates and Obando, 1996) dispersed to South America: Rosen vs. Myers; and (3) whether extant clades occupied Greater Antilles prior to the Eocene-Oligocene boundary: Rosen vs. Iturralde-Vinent and MacPhee.

A well-resolved phylogenetic hypothesis is necessary to critically test these three alternate biogeographical models. Available phylogenetic hypotheses, whether molecular or morphological, have concentrated on single genera or subgenera (Rosen, 1979; Rauchenberger, 1989; Rauchenberger et al., 1990; Meyer et al., 1994; Lydeard et al., 1995; Mojica et al., 1997; Rodriguez, 1997; Ptacek and Breden, 1998; Hamilton, 2001; Mateos et al., 2002; Lucinda and Reis, 2005), or have investigated a limited number of poeciliid fishes within the context of higher level phylogenetic relationships (Ghedotti, 2000). The implicit phylogenetic hypothesis (Parenti and Rauchenberger, 1989) and Fig. 1 of the most comprehensive taxonomic revision of the Poeciliidae (Rosen and Bailey, 1963) is also not suitable to test the alternate biogeographic and life history hypotheses. Therefore, prior to hypotheses testing, we generated a phylogenetic hypothesis for the subfamily Poeciliidae based on a combined analysis of mitochondrial and nuclear DNA data.

\section{Materials and methods}

\subsection{Selection of outgroup and ingroup taxa}

To investigate the phylogenetic relationships of the Poeciliinae, we selected representative members of all known

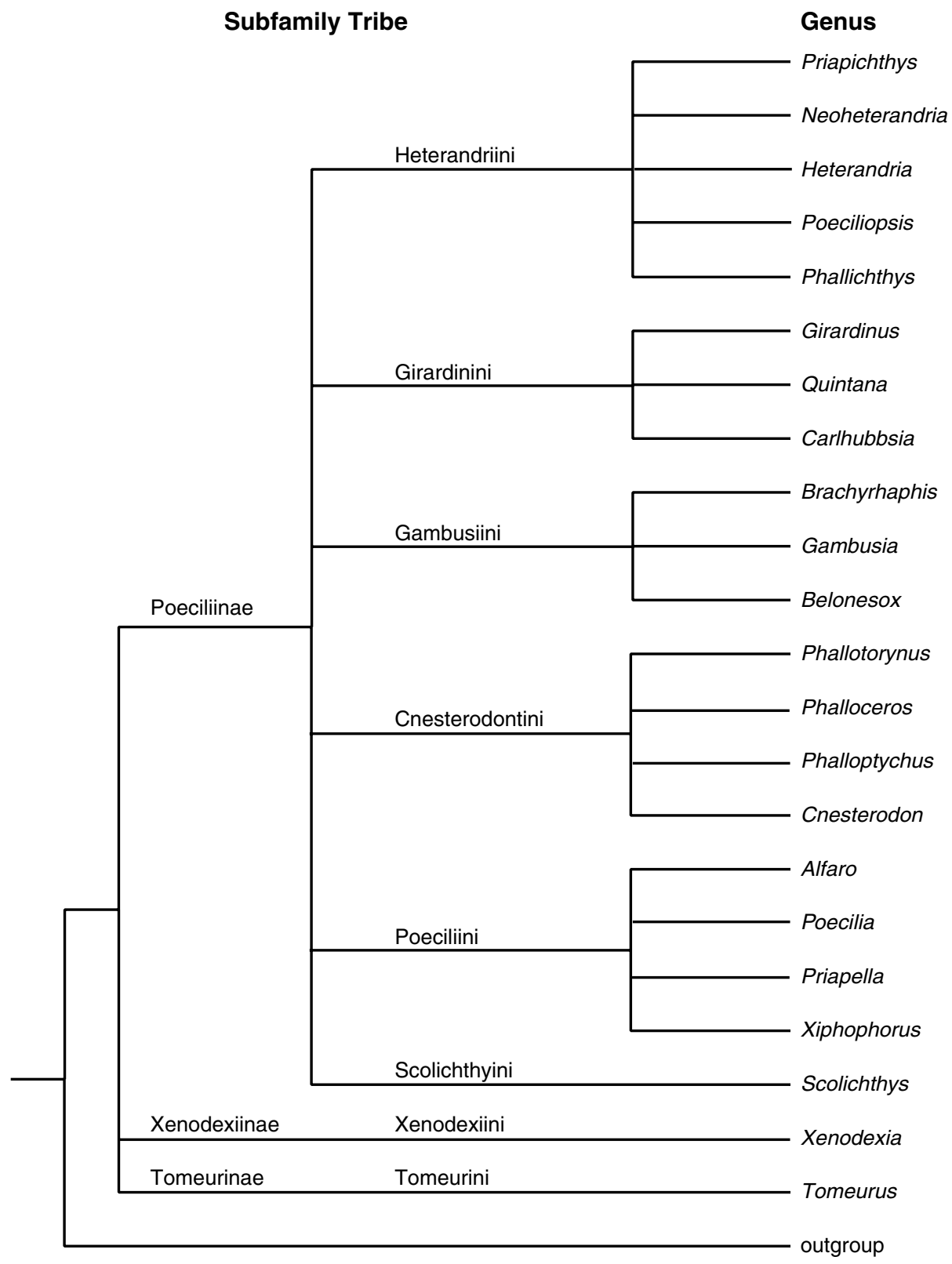

Fig. 1. The taxonomic and the implied phylogenetic hypothesis of the Poeciliinae according to the systematic hypothesis of Rosen and Bailey (1963) and Rosen (1979). 
genera. Species were chosen to represent observed morphological and geographic variation, and to include subgeneric representatives. The phylogenetic relationships of the Cyprinodontiformes are in flux, and thus the choice of the closest outgroups is not obvious. The outgroup genera and species were selected to give a good representation of observed morphological, taxonomical and geographical diversity (Parenti, 1981; Costa, 1998). The outgroups selected included representatives of the subfamily Fluviphylacinae from South America (Fluviphylax pygmaeus) which together with the African Aplocheilichthyinae is traditionally considered to be the sister group to the Poeciliinae (Parenti, 1981), as well as Anableps anableps, Jenynsia maculata and Oxyzygonectes dovii from the family Anablepidae which is considered to be the sister family of the family Poeciliidae (Parenti, 1981). More distantly related outgroups included Profundulus labialis of the family Profundulidae and Empetrichthys latos and Crenichthys baileyi moapae of the family Goodeiae (Parenti, 1981).

\subsection{Laboratory protocols}

Total genomic DNA was extracted from muscle tissue of specimens preserved in $95 \%$ ethanol. Muscle tissue was dissolved and digested with a proteinase K/SDS solution, followed by phenol and chloroform extraction, the addition of $5 \mathrm{M} \mathrm{NaCl}$ followed by $70 \%$ ethanol precipitation of DNA product.

Polymerase chain reaction (PCR) amplification was performed on total genomic DNA. Negative controls were performed for all reactions. The temperature profile for the 30-cycle amplification reaction consisted of denaturation at $94{ }^{\circ} \mathrm{C}$ for $35 \mathrm{~s}$, annealing at $48^{\circ} \mathrm{C}$ for $35 \mathrm{~s}$, and extension at $72{ }^{\circ} \mathrm{C}$ for $90 \mathrm{~s}$ per cycle. Nuclear DNA was amplified according to above protocol, except for a $55^{\circ} \mathrm{C}$ annealing temperature. The resulting products were evaluated on a $1 \%$ agarose gel, and then purified with Qiagen spin-columns. Amplified mtDNA segments were sequenced from both the $5^{\prime}$ and $3^{\prime}$ ends. Sequencing reactions followed standard Perkin Elmer Big Dye sequencing protocol for double-stranded cycle sequencing reactions. Sequences were determined on a Perkin Elmer ABI 3100 automatic DNA sequencer. Amplification and sequencing primers were taken from the literature or designed specifically for this study (Table 1). The mtDNA region analyzed included the complete cytochrome $b$ gene; a segment consisting of $3^{\prime}$ half of the $12 \mathrm{~S}$ rRNA, the tRNA ${ }^{\mathrm{Val}}$, and the $5^{\prime}$ end of the 16S rRNA; a third contiguous segment consists of the $3^{\prime}$ end of the 16S rRNA, tRNA ${ }^{\text {Leu }}$, the genes encoding the NADH dehydrogenase subunit 1 , tRNA ${ }^{\text {Ile }}$, tRNA ${ }^{\text {Gln }}$,

Table 1

Primers used in this study

\begin{tabular}{|c|c|c|c|}
\hline Location & Gene & Sequence & Source \\
\hline L14725 & tRNA $^{\text {Glu }}$ & 5'-GAYTTGAARAACCAYCGTTG-3' & This study ${ }^{\mathrm{a}}$ \\
\hline H15982 & tRNA $^{\text {Pro }}$ & 5'-CCTAGCTTTGGGAGYTAGG-3' & This study \\
\hline L1090 & $12 \mathrm{~S}$ & 5'-AAACTGGGATTAGATACCCCACTA-3' & Hrbek and Larson (1999) \\
\hline H1782 & $16 \mathrm{~S}$ & 5'-TTTCATCTTTCССТTGCGGTAC-3' & Hrbek and Larson (1999) \\
\hline H3058 & $16 \mathrm{~S}$ & 5'-CCGGTCTGAACTCAGATCACGT-3' & Kessing et al. (1989) \\
\hline L3002 & $16 \mathrm{~S}$ & 5'-TACGACCTCGATGTTGGATCAGG-3' & Hrbek and Meyer, 2003 \\
\hline L3079 & $16 \mathrm{~S}$ & 5'-ACGTGATCTGAGTTCAGACCG-3' & Hrbek and Meyer (2003) \\
\hline L3899 & ND1 & 5'-GAAACAAACCGAGCCCCYTT-3' & Hrbek and Meyer (2003) \\
\hline H4280 & $\mathrm{tRNA}^{\mathrm{Ile}}$ & 5'-ACTGTATCAAAGTGGYCCTT-3' & Hrbek and Meyer (2003) \\
\hline L4299a & $\mathrm{tRNA}^{\mathrm{Ile}}$ & 5'-AAGGRTTACTTTGATAGAGT-3' & Hrbek and Larson (1999) \\
\hline L4299b & $\mathrm{tRNA}^{\mathrm{Ile}}$ & 5'-AAGGRCCACTTTGATAGAGT-3' & Hrbek and Meyer (2003) \\
\hline H4419 & tRNA $^{\text {Met }}$ & 5'-AAGCTTTYGGGCCCATACC-3' & Hrbek and Meyer (2003) \\
\hline L4882a & ND2 & 5'-TGACAAAARCTAGCCCC-3' & Hrbek and Larson (1999) \\
\hline L4882b & ND2 & $5^{\prime}$-TGACAAAARCTAGCACC-3' & Hrbek and Larson (1999) \\
\hline L4882c & ND2 & 5'-TGACAAAAAYTTGCTCC-3' & Hrbek and Larson (1999) \\
\hline H4980a & ND2 & 5'-CGKAGTTGRACTTGGTT-3' & This study \\
\hline $\mathrm{H} 4980 \mathrm{~b}$ & ND2 & 5'-CGKAGTTGRACTTGATT-3' & This study \\
\hline H5540a & $\mathrm{tRNA}^{\mathrm{Trp}}$ & 5'-TTTAGRGCTTTGAAGGC-3' & Hrbek and Larson (1999) \\
\hline L5554 & tRNA $^{\operatorname{Trp}}$ & 5'-CCAAGRGCCTTCAAAGCCCT-3' & Hrbek and Meyer (2003) \\
\hline H5934 & $\mathrm{CO} 1$ & 5'-AGRGTGCCAATGTCTTTGTGRTT-3' & Macey et al. (1997) \\
\hline L2492 & RAG1ex3 & 5'-CCWGCTGTITGYYTGGCCATIMG-3' & H. Brinkmann pers.com. \\
\hline L2891 & RAG1ex3 & 5'-AAGGAGTGYTGYGATGGCATGGG-3' & This study \\
\hline H2932 & RAG1ex3 & 5'-GAGAARCGRACAGCCTTYTC-3' & This study \\
\hline L3371 & RAG1ex3 & 5'-GARCGYTAYGAAATATGGAG-3' & This study \\
\hline H3405 & RAG1ex3 & 5'-GCNGAGACTCCTTTGACTCTGTC-3' & This study \\
\hline H3405 & RAG1ex3 & 5'-GCNGAGACTCCTTTGACTCTGTC-3' & This study \\
\hline H4035a & RAG1ex3 & 5'-TGYTTTCAGCACATCCTCCARCTC- $3^{\prime}$ & This study \\
\hline H4054 & RAG1ex3 & 5'-GTGTAGAGCCARTGRTGYTT-3' & Martin (1999) \\
\hline
\end{tabular}

The primer designation corresponds to its $3^{\prime}$ position in the human mitochondrial genome (Anderson et al., 1981) by convention. $\mathrm{H}$ and $\mathrm{L}$ designate primers that extend the heavy strand and the light strand, respectively. Positions with mixed bases are labeled with standard mixed-base codes: $\mathrm{R}=\mathrm{G}$ or $\mathrm{A} ; \mathrm{Y}=\mathrm{C}$ or $\mathrm{T} ; \mathrm{S}=\mathrm{C}$ or $\mathrm{G} ; \mathrm{I}=$ Inosine. Designations of RAG 1 primers correspond to $3^{\prime}$ position in the zebrafish (Danio rerio).

${ }^{a}$ Modified from (Kessing et al., 1989). 
tRNA $^{\text {Met }}$, NADH dehydrogenase subunit 2, tRNA ${ }^{\text {Trp }}$, tRNA $^{\text {Ala }}$, tRNA ${ }^{\text {Asn }}$, tRNA ${ }^{\text {Cys }}$, tRNA ${ }^{\text {Tyr }}$, the $5^{\prime}$ end of the subunit 1 of cytochrome $c$ oxidase, and including the replication origin for the light strand $\left(\mathrm{O}_{\mathrm{L}}\right)$ between the tRNA $^{\text {Asn }}$ and tRNA ${ }^{\text {Cys }}$ genes. Nuclear gene analyzed was the third exon of RAG1. The gene regions were selected to include both faster and slower evolving regions in order to maximize the likelihood of obtaining phylogenetic resolution of recent as well as more ancient cladogenic events.

\subsection{Data analysis}

Homologous protein-coding regions (Cyt $b$, NADH1, NADH2, RAG1) were aligned manually and confirmed by translating DNA data into amino acid sequences in BioEdit (Hall, 1999). Alignments of ribosomal and transfer RNAs were constructed manually based on secondary structural models (Kumazawa and Nishida, 1993; Ortí and Meyer, 1997; Waters et al., 2000). The mtDNA data set included a total of 4333 alignable characters representing 48 ingroup and seven outgroup taxa; 2607 of these characters were variable and 2184 were parsimony informative. We excluded the loop of the d-arm of the tRNA ${ }^{\text {Cys }}$ and the loop of light strand replication origin since these regions were unalignable. The nuclear data set included a total of 1542 alignable characters; 509 of these characters were variable and 308 were parsimony informative. All mtDNA sequences were tested for an anti-G bias characteristic of the mitochondrial DNA genes, to confirm that we have collected genuine mitochondrial DNA data (Zhang and Hewitt, 1996). All sequence data have been deposited in GenBank under the Accession Nos. EF017508-EF017557 (Cyt b), EF017456-EF017507 (12S), EF017558- EF017607 (ND1 + ND2), and EF017405EF017455 (RAG1). A file with the aligned data is available directly from the first author.

The mitochondrial and the nuclear data sets were initially analyzed separately, however, the topologies obtained from the mitochondrial and nuclear genes did not differ significantly (Shimodaira-Hasegawa test, $P>0.05$ ). The mitochondrial and nuclear DNA partitions did not exhibit incongruence (partition-homogeneity test, $P>0.05$ ), thus the data sets were combined, and all subsequent analyses were done on the combined nuclear and mitochondrial DNA data.

Maximum likelihood based phylogenetic relationships were estimated using the program PAUP* (Swofford, 2002) and implementing a full heuristic search of the tree space. ModelTest vers. 3.04 (Posada and Crandall, 1998) indicated that the best-fit model of nucleotide substitution was the general-time-reversible model with some sites assumed to be invariable and with variable sites following a discrete gamma distribution $(\mathrm{GTR}+\mathrm{I}+\Gamma)$. Therefore the GTR $+\mathrm{I}+\Gamma$ model (Rodríguez et al., 1990) of evolution with rate heterogeneity, rates for variable sites assumed to follow the gamma distribution with shape parameter esti- mated by the maximum likelihood method was used to arrive at the topology with the highest likelihood.

Bayesian likelihood based phylogenetic relationships were estimated using the program MrBayes 2.01 (Huelsenbeck and Ronquist, 2001) and implementing a full heuristic search of the tree space. The data were partitioned into 14 classes (rDNA, tRNA and base positions 1, 2 and 3 of cyt $b$, NADH1, NADH2, and RAG1). A site specific GTR $+\mathrm{I}+\Gamma$ model of evolution with rate heterogeneity, rates for variable sites assumed to follow the gamma distribution with shape parameter estimated by the maximum likelihood was used. We ran 5,000,000 generations, sampling trees and branch-length every 100 generations. Since likelihoods stabilized within the first 500,000 runs, we discarded the lower $10 \%$ of the trees as burnin trees in the computation of a $50 \%$ majority rule consensus tree. Following Huelsenbeck and Ronquist (2001) the percent of times a clade occurs among the sampled trees was interpreted as the probability of that clade existing. These probabilities are true probabilities under the assumed model of substitution (Rannala and Yang, 1996); thus we considered clades to be significantly supported when Bayesian posterior probabilities were $<95 \%$.

Estimates of divergence times of nodes of the maximumlikelihood phylogeny were done with the program r8s using the semi-parametric penalized likelihood approach of divergence times estimation (Sanderson, 2002) since the data showed a partial clock-like behavior (LRT test; $\chi^{2}=65.983, v=54, p>0.05$ ). Our phylogeny was constrained to conform to previously estimated divergence times for the genus Poeciliopsis (Mateos et al., 2002; Reznick et al., 2002). Specifically, we used the data set of Mateos et al. (2002) under the constraint parameters of Reznick et al. (2002) to arrive at a 19.43 (95\% CI 15.51-23.87) million year divergence of the species pair $P$. fasciata/P. hnilic$k a i$, a species pair in common to all studies.

Hypotheses of diversification of poeciliids were derived from Rosen (1975), Myers (1966), and Iturralde-Vinent and MacPhee (1999), and the publications of Coates and Obando (1996) and Keigwin (1982). Competing hypotheses were tested for temporal and pattern congruence with the maximum-likelihood phylogenetic hypothesis.

\section{Results}

\subsection{Phylogenetic relationships}

We conducted separate sets of analyses for the mtDNA partition, the nuclear DNA partition and for the combined data set. The analyses of the mtDNA and the nuclear DNA data sets resulted in non-significantly different, but in general poorly supported phylogenetic hypotheses differing only in the phylogenetic relationships among major geographic clades of poeciliids. Analyses of the combined mtDNA and nuclear DNA data sets resulted in well-supported phylogenetic hypotheses that were consistent among analyses (Figs. 2 and 3). 


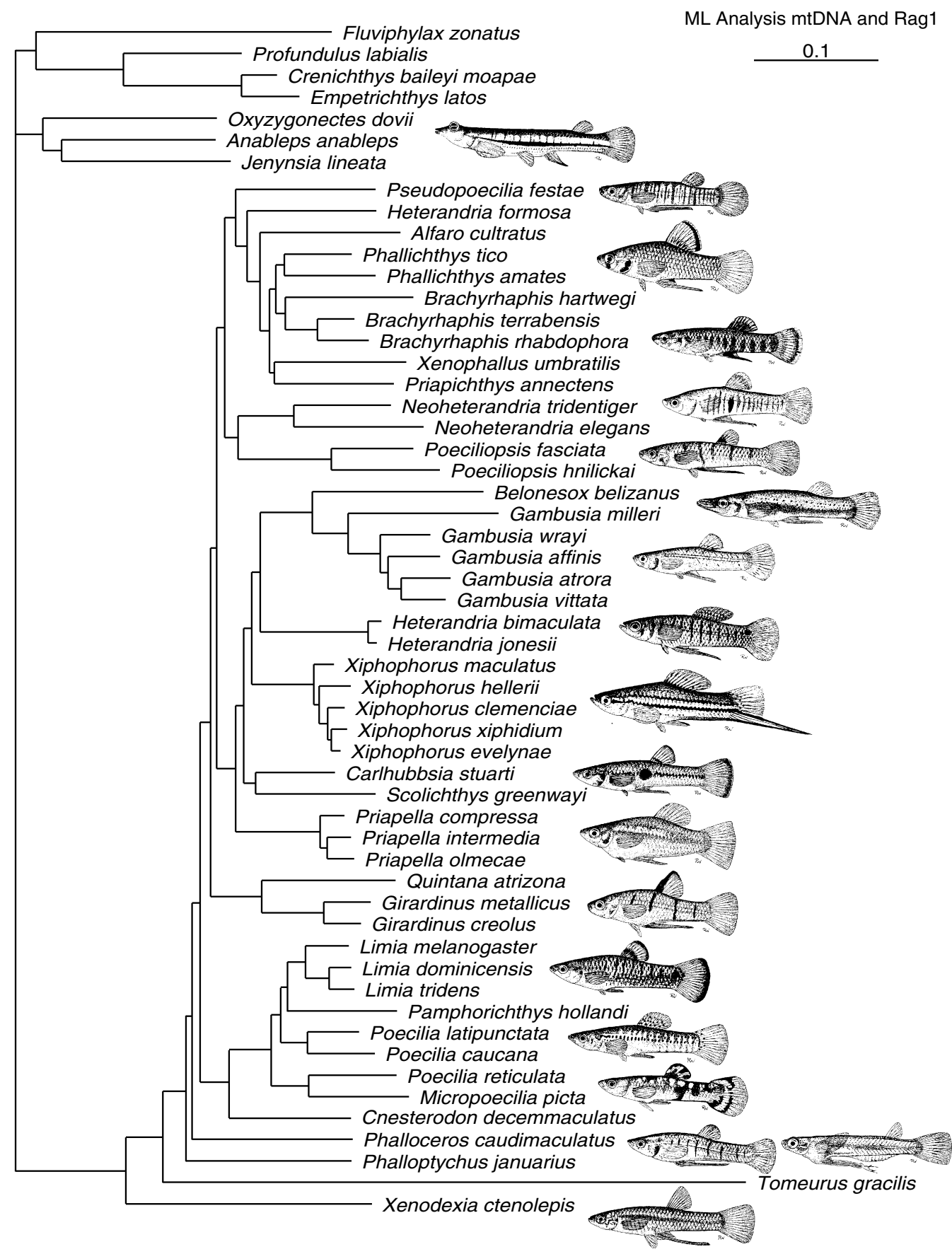

Fig. 2. A maximum likelihood hypothesis of phylogenetic relationships of the Poeciliinae. Generic names follow Lucinda (2003). The parameters for the GTR $+\mathrm{I}+\Gamma$ model of nucleotide substitution are as follows: $\Gamma$ shape parameter $\alpha=0.632242, I=0.362948$ with a $-\ln =87395.56724$.

In the mtDNA partition, the base pair composition (average $\mathrm{A}=0.263, \mathrm{C}=0.294, \mathrm{G}=0.174, \mathrm{~T}=0.269$ ) show anti-G bias characteristic of mitochondrial genes but not of nuclear genes (Meyer, 1993; Zhang and Hewitt, 1996). Over all, the data show little saturation, however, a moderate amount of saturation exists in the third positions of cytochrome $b$, NADH1 and NADH2 genes. No saturation is observed in the RAG1 gene. The transition/transversion ratio is 3.14 for the mtDNA data, and 4.87 for the nuclear data, with a combined transition/transversion ratio of 3.50. Our data also contain a large number of informative characters, both within the ingroup, and between the outgroup and the ingroup. Within the mtDNA data set, the number of parsimony informative characters (2190) was more than 42 times the number of taxa (55) sampled. Of the 2190 parsimony informative characters, the data contain 1437 parsimony informative characters that span the internodes among the nine main geographic clades. In spite of the large number of parsimony informative characters in the mtDNA data set, the mtDNA data 


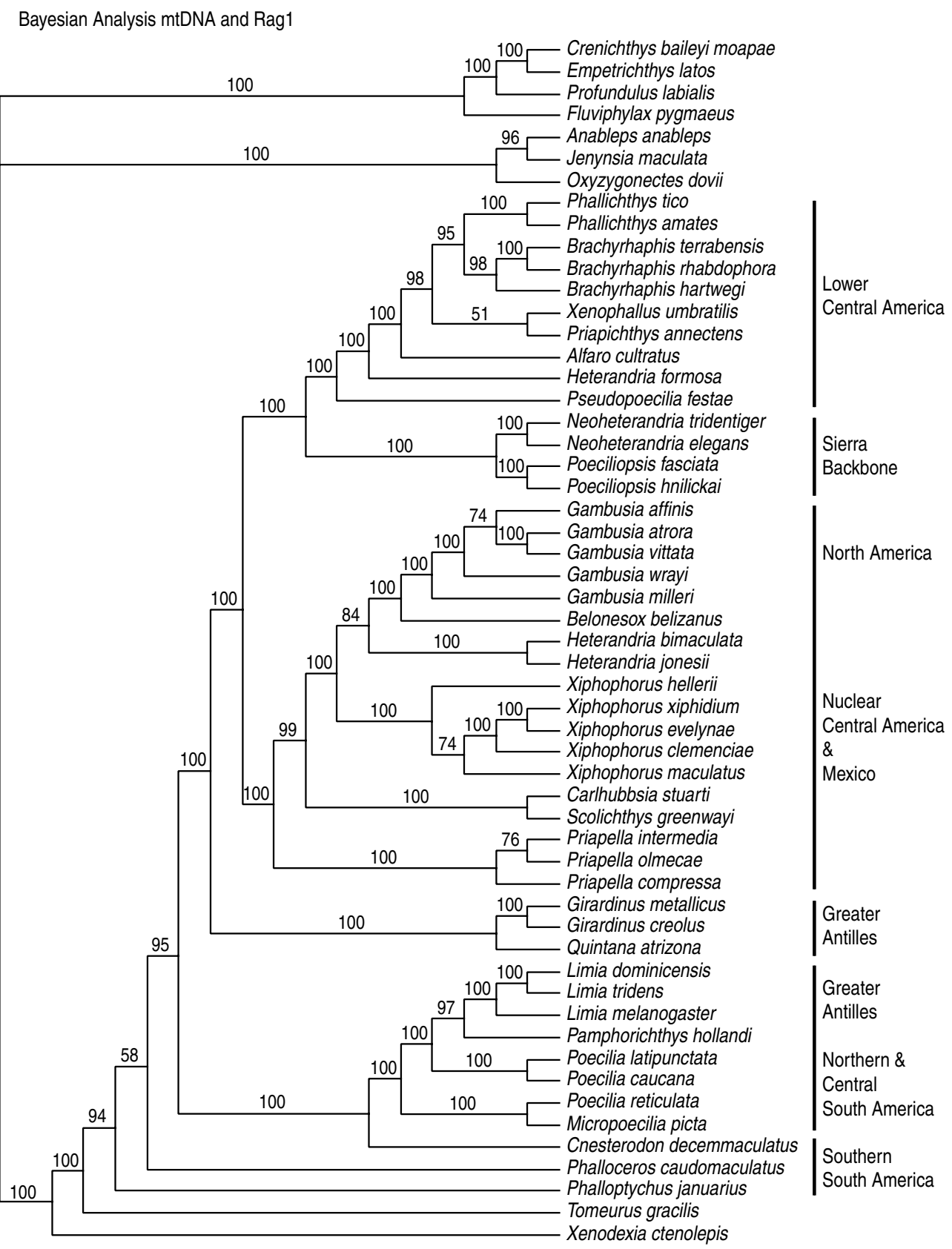

Fig. 3. A Bayesian likelihood hypothesis of phylogenetic relationships of the Poeciliidae. Bayesian likelihoods are listed above nodes. See text for details of the analysis.

set alone is unable to resolve the phylogeny of the Poeciliinae.

In our study we find that Xenodexia ctenolepis is sister to all other poeciliids and T. gracilis is sister to all Poeciliinae but Xenodexia (Figs. 2 and 3). This phylogenetic hypothesis suggests that internal fertilization and live-bearing may been present in the ancestor of the Poeciliinae, with livebearing being lost in the species $T$. gracilis. The secondary loss of live-bearing in $T$. gracilis also has been suggested by Ghedotti (2000), and this finding is also supported by phylogenetic analysis of the whole order Cyprinodontiformes (TH in prep.). Within the Poeciliinae many of the genera are not monophyletic (Figs. 2 and 3), and the tribes (Fig. 1) as defined by Rosen and Bailey (1963) are not natural. We also statistically reject the monophyly of all tribes that appear non-monophyletic in our phylogeny (Table 2). In all instances where genera are para- or polyphyletic we statistically reject their monophyly as well (Table 2).

\subsection{Zoogeography}

Although our study does not agree with the traditional taxonomic classification (Rosen and Bailey, 1963), our phylogeny consists of nine major geographically restricted 
Table 2

Tests of phylogenetic hypotheses

\begin{tabular}{|c|c|c|c|c|}
\hline \multicolumn{3}{|c|}{ Kishino and Hasegawa (1989) and Shimodaira and Hasegawa (1999) } & \multirow{2}{*}{$\begin{array}{l}\text { KH-test } \\
P\end{array}$} & \multirow{2}{*}{$\begin{array}{l}\text { SH-test } \\
P\end{array}$} \\
\hline Tree & -ln Likelihood & Diff $-\ln L$ & & \\
\hline ML tree & 87395.56724 & & & \\
\hline Rosen and Bailey phylogeny & 88149.91547 & 754.34823 & $0.000^{*}$ & $0.000^{*}$ \\
\hline Heterandriini monophyly & 87780.49553 & 384.92829 & $0.000^{*}$ & $0.000^{*}$ \\
\hline Girardinini monophyly & 87488.09171 & 92.52448 & $0.000^{*}$ & 0.088 \\
\hline Gambusiini monophyly & 87850.68970 & 455.12247 & $0.000^{*}$ & $0.000^{*}$ \\
\hline Cnesterodontini monophyly & 87456.05420 & 60.48697 & $0.000^{*}$ & 0.292 \\
\hline Poeciliini monophyly & 87759.46649 & 363.89925 & $0.000^{*}$ & $0.000^{*}$ \\
\hline Heterandria monophyletic & 88002.13887 & 606.57163 & $0.000^{*}$ & $0.000^{*}$ \\
\hline Neoheterandria monophyletic & 87487.56709 & 91.99985 & $0.000^{*}$ & 0.122 \\
\hline Priapichthys monophyletic & 87447.89365 & 52.32641 & $0.002^{*}$ & 0.370 \\
\hline
\end{tabular}

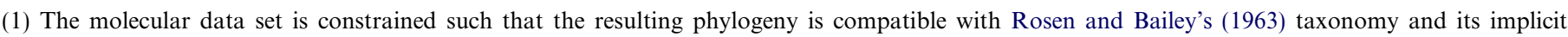

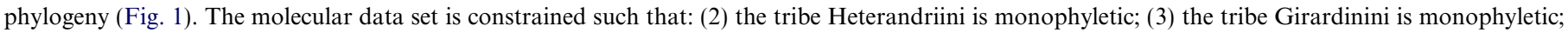

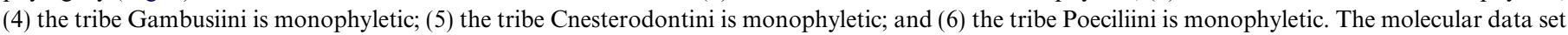

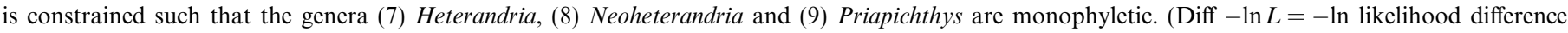

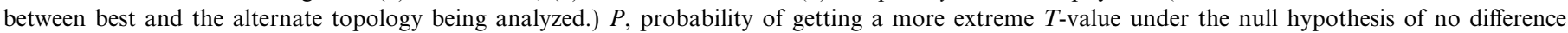
between the two trees (KH two-tailed test, $\mathrm{SH}$ one-tailed test).

* Significant at $P<0.05$.

clades that to a large extent agree with neotropical biogeographical units. The Caribbean realm contains five major geographic regions or components, but some regions contain members of more than one clade (Fig. 4). The geographical regions based on poeciliid distributional data are thus largely concordant with regions defined by Savage (1966), Savage (1982) and Rosen (1975), based on herpetofaunal and ichthyofaunal distributional patterns, respectively, and reflect the geological events shaping the neotropics (Briggs, 1994) and Central American and Carribean regions in particular (Keigwin, 1982; Coates and Obando, 1996; Iturralde-Vinent and MacPhee, 1999).

Based on an extensive analysis and critical review of geological literature Iturralde-Vinent and MacPhee (1999) proposed that none of the geological components of the Greater Antillean islands became permanently emergent until the Eocene-Oligocene transition (35-33 Mya). At this point the Greater Antilles were also connected to northern South American through what now is the submerged Aves Ridge. The authors also hypothesize that Middle Central America was connected to northern South American from the late period of Campanian (83.5-71.3 Mya) to early period of Maastrichtian (71.3-65 Mya) of the Jurassic Period, thereafter evidence of any potential connection disappeared. The formation of Lower Central America and the resulting connection is a process that began approximately 15 Mya with land being added onto Middle Central America (Coates and Obando, 1996). This process terminated with the formation of a permanent connection between North and South America across eastern Panama and the Choco region of Colombia approximately 3.53 Mya (Keigwin, 1982; Coates and Obando, 1996). Rosen hypothesized that a Cretaceous (144-65 Mya) connection existed between South and North America and that during this time the Antilles were populated by poeciliids. On the other hand, Myers (1966) considered this scenario as unlikely. He only considered a Pliocene (5.3-1.8 Mya) connection between South and North America possible, and presented no hypothesis for the colonization of the Greater Antilles.

We tested our maximum-likelihood phylogenetic hypothesis of phylogenetic relationships specifically for temporal agreement with these geological events. The estimated divergence time of 67.98 Mya $(95 \%$ CI $62.81-$ $74.30 \mathrm{Mya}$ ) at the deepest node separating $X$. ctenolepis from all other poeciliid fishes agrees with the late Campanian to early Maastrichtian connection of Middle Central America and northern South America. The timing of the divergence between the predominantly South American poeciliids and the non-South American poeciliids is estimated at 43.91 Mya (95\% CI 40.78-48.97 Mya). This divergence estimate may be compatible with a second invasion of Central and North America via the Aves land bridge thought the Greater Antilles 35-33 Mya since a basal split within the non-South American clade occurs between taxa found on Cuba and those inhabiting mainland Central and North America. Whether taxa dispersed over salt water from the Antilles to Central America, or if these land masses were connected is not known. The genus Limia which is deeply nested within Poecilia sensu lato represents a later colonization event of the Greater Antilles. This colonization event occurred at some point after 19.93 Mya $(95 \%$ CI $18.04-22.17 \mathrm{Mya}$ ) and may possibly represent a same colonization/dispersal event to the Greater Antilles by the genus Gambusia (13.49 Mya, 95\% CI 12.0615.19 Mya). However, our taxonomic sampling within these clades is not sufficiently detailed to confidently test these hypotheses. No poeciliids invaded Central America as a result of the recent closing of the Isthmus of Panama 3.5-3 Mya, although our data support a hypothesis of colonization of the trans-Andean regions of South America by taxa or lineages originating in Central America. 


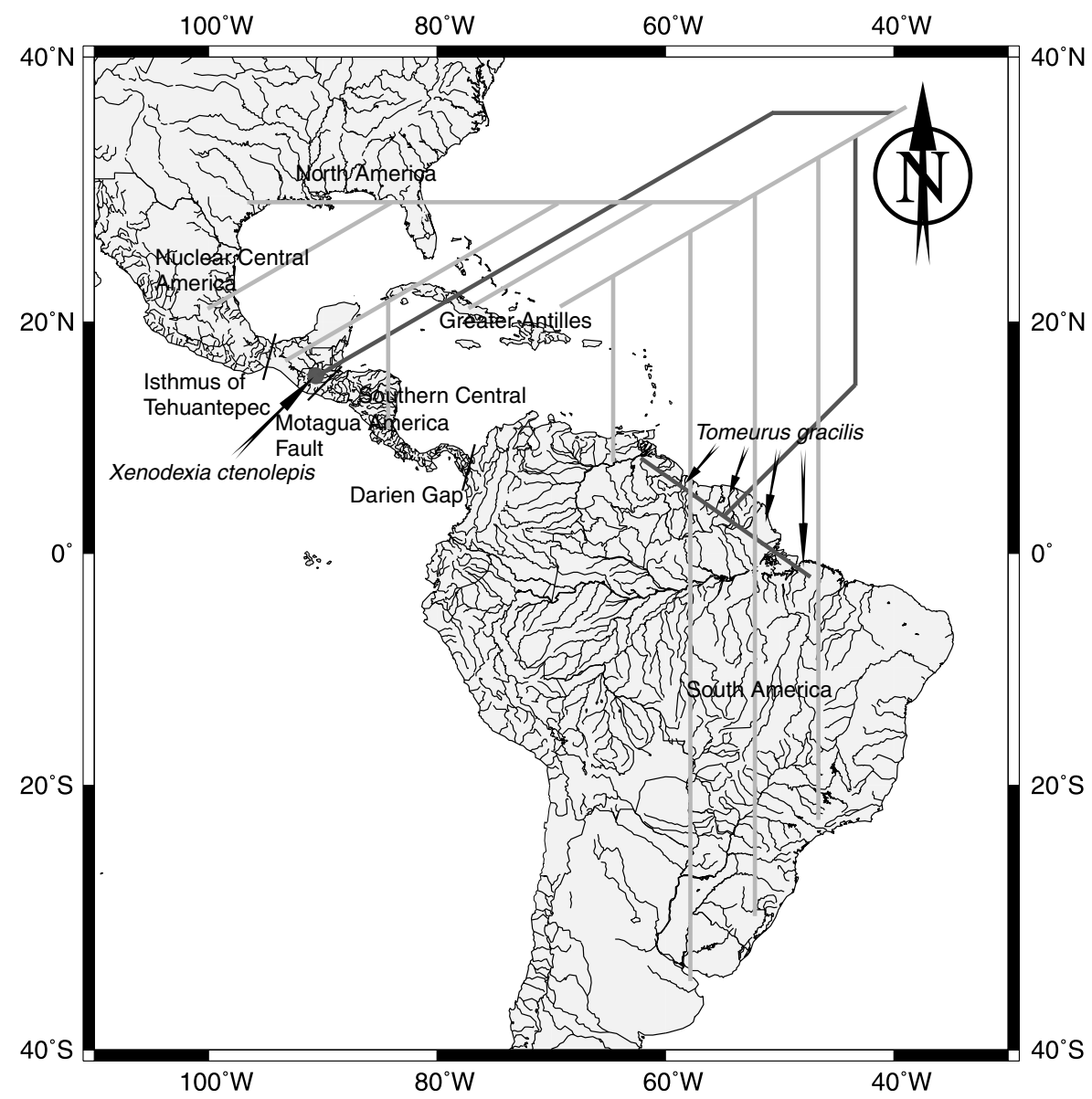

Fig. 4. A map of poeciliid distribution and area relationships of major biogeographical areas. The dark branch leading to Xenodexia ctenolepis emphasizes its probable Cretaceous dispersal into Middle American from South America, and the dark branch leading to Tomeurus gracilis emphasizes its egg-laying life history.

\section{Discussion}

The subfamily Poeciliinae is widely distributed and occurs in the southeastern and southwestern United States, Mexico, Central America, South America and the Caribbean. Poeciliids are a conspicuous faunal component of Central America accounting for approximately $35 \%$ of the its secondary freshwater fish fauna (Miller, 1966); only the family Cichlidae is comparable in diversity. Based on distributional data of poeciliid genera and/or subgenera there are five distinct geographic regions (Fig. 4): South America-Tomeurus, Phalloceros, Phallotorynus, Phalloptychus, Cnesterodon, Poecilia; Nuclear Central America- (includes the ichthyofaunal based Usumacinta province of Bussing (1976) plus parts of the San Juan province for the genera Alfaro and Phallichthys), Carlhubbsia, Belonesox, Priapella, Alfaro, Xiphophorus, Heterandria (Pseudoxiphophorus), Poecilia, Gambusia, Phallichthys, Xenodexia, Scolichthys, Poeciliopsis; Southern Central America-(both Pacific and West Coast drainages and parts of northern South America in some cases), Brachyrhaphis, Priapichthys, Neoheterandria, Poeciliopsis, Poecilia, Gambusia; North America-Heterandria, Poecilia, Gambusia; and the
Greater Antilles-Gambusia, Limia, Quintana, Girardinus. The component definitions based on poeciliid distributional data are largely concordant with area components defined by Savage (1966), Savage (1982) and Rosen (1975) based on all herpetofaunal and ichthyofaunal distributional patterns, respectively. The poeciliid geographic areas are occupied largely by monophyletic lineages, although South America is paraphyletic and genera such as Gambusia and Poecilia are widespread.

\subsection{Zoogeography of poeciliidae}

Rosen (1975) published a seminal paper on the zoogeography of the Caribbean with an emphasis on Central American and Caribbean fishes, and proposed a plate tectonicbased vicariance model for this region. His hypothesis sharply contrasted with that of Myers (1966) who found no support for a Cretaceous connection between Central and South America. More recently a geological model of Caribbean evolution was proposed by Iturralde-Vinent and MacPhee (1999). These three main biogeographical models of the Caribbean realm differ in three not necessarily mutually exclusive points: (1) whether or not a Cretaceous 
and a Pliocene, or only a Pliocene connection existed between Central and South America: Rosen, and Iturralde-Vinent and MacPhee vs. Myers; (2) whether poeciliids were a wide-spread group in the Central and South America region, or if they were restricted to Central America, and only subsequent to the formation of the Isthmus of Panama 3.5-3 million years ago (Keigwin, 1982; Coates and Obando, 1996) dispersed to South America: Rosen vs. Myers; and (3) whether extant clades occupied Greater Antilles prior to the Eocene-Oligocene boundary: Rosen vs. IturraldeVinent and MacPhee.

Our results address these three points explicitly. A late Cretaceous connection between Middle and South America appears to have existed, in principle allowing bi-directional dispersal between north and south. Poeciliids are an ancient group initially restricted to its South American area of origin, that have undergone an additional vicariancedriven radiation in Nuclear Central America, the Greater Antilles and Southern Central America, following dispersal into these regions from South America. The main colonization of Middle and North America most likely occurred though Greater Antilles around the time of the Eocene-Oligocene transition.

We tested our maximum-likelihood phylogenetic hypothesis of phylogenetic relationships specifically for temporal agreement with geological events associated with the formation of the Caribbean and Central America (Keigwin, 1982; Coates and Obando, 1996; IturraldeVinent and MacPhee, 1999). The estimated divergence of $X$. ctenolepis from all other poeciliids is approximately 68 million years ago (67.98 Mya, 95\% CI 62.81-74.30 Mya), which agrees well to the late Campanian to early Maastrichtian connection of Middle Central America and northern South America (Iturralde-Vinent and MacPhee, 1999). The main radiation of poeciliid fishes occurred approximately 44 million years ago (43.91 Mya, 95\% CI 40.7848.97 Mya) which may be compatible with a second invasion of Central and North America via the Aves land bridge thought the Greater Antilles 35-33 million years ago (Iturralde-Vinent and MacPhee, 1999). This hypothesis is supported by a basal split between taxa found in Cuba and those found on mainland Central and North America. Both of these colonization events as well as the 21.92 million year (95\% CI 19.92-24.39) invasion of Central and North America by the Mollinesia subgenus of Poecilia precede the final closing of the Isthmus of Panama 3.5-3 million years ago. More recent colonization events include the hypothesized dispersal of Limia (Poecilia sensu lato) and Gambusia into the Greater Antilles 19.93 and 13.49 million years ago, respectively. While many of the estimated divergence times are older than commonly assumed, these estimates are consistent with poeciliid divergences estimated within the framework of the order Cyprinodontiformes which use independent calibration points $(\mathrm{TH}$ in prep.). Furthermore, recent studies of Lower Central American fishes of South American origin support a hypothesis of mid-Miocene as well as mid-Pliocene colonization events (e.g. Bermingham and Martin, 1998; Perdices et al., 2002).

Poeciliids dispersed at least three times between South America and Middle America. One event is represented by the divergence of $X$. ctenolepis (Guatemala) from $T$. gracilis (the Guyanas and the states of Amapá and Pará, Brazil) plus all its sister taxa. This even may represent a dispersal into Central America or a fragmentation followed by an extinction of all Central American species but X. ctenolepis. The second dispersal event resulted in the main poeciliid radiation of Central America and the Antilles. This clade is statistically well supported, and is nested within a paraphyletic and predominantly South American group. The third dispersal involves the non-South American members of this predominantly South American paraphyletic group. They are the nested members of Poecilia sensu lato that have dispersed to the Greater Antilles (now the genus Limia) and Atlantic Central America as far north as the Carolinas, USA (the subgenus Mollienesia). The fishes of the genera Poeciliopsis, Neoheterandria and Priapichthys may represent additional dispersals between South America and Central America in the direction of the Chocó region of Colombia. Our phylogenetic hypothesis places Poeciliopsis and Neoheterandria (excluding $N$. umbratilis $=$ Xenophallus umbratilis) as the sister group to the Lower Central American clade (Figs. 2 and 3). Poeciliopsis species are distributed along the Sierra Nevada Backbone of Central America ranging from northern Mexico and southern Arizona, USA south to the Chocó region of Colombia, while Neoheterandria occur just past the Panama-Colombia border. The apparently paraphyletic Priapichthys has several species in the Chocó with Priapichthys (=Pseudopoecilia) festae reaching as far south as Guyaquil basin of Equador. Based on our phylogenetic hypothesis and that of Mateos et al. (2002), the origin of this clade is clearly in Lower Central America. With these exceptions, the basal South American group occurs south of, and the main poeciliid radiation of Central America occurs north of the Darien gap, i.e. the point of closure and junction of Central American and South America (Fig. 4).

Vicariant events likely continued to shape the main Central American radiation. The Central American radiation consists of four major geographic sub-clades represented on three geological units (Greater Antilles, Nuclear Central America and North America, Lower Central America). These areas have to a large extent acted separately of each other at various times throughout the geological development of the area (Coney, 1982). Marine connections existed between the Pacific and Atlantic oceans through the Isthmus of Tehuantepec and the Motagua Fault (continuing as the Cayman Trench) that form the northern and the southern limits of the Lower Central American and the Nuclear Central American clades, respectively. The fourth major geographic sub-clade comprising the genera Poeciliopsis and Neoheterandria occurs on the above discussed Sierra Nevada Backbone. We hypothesize this clade 
diverged from its sister Lower Central American clade along an altitudinal cline within Lower Central America, and subsequently dispersed north and south from its center of origin along the Sierra Nevada Backbone.

The most likely scenario for the evolutionary history of the Poeciliinae would thus be South American origin with recurrent dispersal to Middle and North America. With the exception of the Guatemalan X. ctenolepis, basal poeciliid taxa are South American, and the South American base is paraphyletic. Additionally, poeciliid fishes are thought to form a sister clade to the aplocheilichthyiine killifishes (Parenti, 1981; Meyer and Lydeard, 1993; Costa, 1998) that, with the exception of the Amazonian genus Fluviphylax and the Malagasy Pantanodon madagascariensis, are distributed in sub-Saharan African.

Poeciliids are an ancient clade whose origins precede the basal Cretaceous split between the Middle American Xenodexia and all other species. They colonized the Greater Antilles and Middle America a second time, possibly over the Aves land bridge during the late Eocene. Subsequent events include Oligocene vicariance in Central America, and Pliocene dispersals to the Greater Antilles. The closing of the Isthmus of Panama in the late Pliocene did not result in any new poeciliid colonization events from South America, but allowed Central American poeciliids to colonize trans-Andean regions of South America. The spatial and temporal pattern of the poeciliid phylogeny supports the models of Iturralde-Vinent and MacPhee (1999) and of Rosen (1975) in part, while the model of Myers (1966) is not supported. While dispersal over land bridges appears to have played a major role in the diversification of the Poeciliinae, so did dispersal over water barriers as did classic vicariant processes. These diversification mechanisms are usually presented as discrete, mutually exclusive alternatives, but in many taxonomic groups, including the Poeciliinae, it seems inescapable that all three mechanisms made significant contributions to the presentday distribution of poeciliid diversity.

\subsection{A note on poeciliid taxonomy}

The current taxonomy (Rosen and Bailey, 1963) of the Poeciliinae and their assignment to the tribes is based primarily on gonopodial characters. The tribe Poeciliini has a relatively short gonopodium and a moderately specialized gonopodial suspensorium. In the Cnesterodontini, the gonopodium is shifted far forward, with the necessary susponsorial modifications, and the gonopodium is elongate. The Gambusiini are the least specialized, with a short to medium length gonopodium, and a short gut. The Girardinini have a long and complexly modified gonopodium, and a long and coiled gut. The Heterandriini have comparable modifications as the Giradinini, although the gonopodial tip is usually simpler, and they are unified by common suspensorial specializations. These and other presumed shared derived traits are summarized in Table 3 of Rosen and Bailey (1963). Three of the original eight tribes are monotypic. Monophyly of three of the five remaining tribes is rejected statistically in our analyses (Table 2). A recent morphological analysis (Ghedotti, 2000) of 12 poeciliid species representing six of the eight tribes also suggests that a number of the tribes are not monophyletic, as does the study of Lucinda and Reis (2005).

The characters used to place individual species into genera and genera into tribes by Rosen and Bailey (1963) evidently have evolved multiple times, possibly in response to similar ecological pressures or due to sexual selection (Langerhans et al., 2005). Hence, many of the gonopodial similarities of species that are currently assigned to, based on our study, polyphyletic tribes are therefore presumably largely attributable to homoplasy and cannot serve as taxonomically reliable characters. Since our molecular phylogeny is consistent with geological events shaping Central and South America, and clades as defined by the molecular phylogeny are geographically restricted (Figs. 3 and 4), we suggest a need for a taxonomic re-evaluation of the Poeciliinae. However, a taxonomic re-evaluation utilizing both morphological and molecular characters should be done with caution in light of recent evidence of hybridization among Xiphophorus species (Meyer et al., 2006).

\section{Acknowledgments}

We thank Biff Bermingham, Godfrey Bourne, Jaap Jan de Greef, Jerry Johnson, Robert McKeenand, Manfred Meyer, Alex Parker, David Reznick, Donald C. Taphorn, Joel Trexler, and Shane Webb for providing or helping us to obtain specimens, and Kai N. Stölting and Ursula Topel for help in the laboratory. Rudolf $\mathrm{H}$. Wildekamp provided drawings of poeciliids. Discussions with Jim Cheverud, Mariana Mateos, David Reznick and Mark Springer improved the manuscript. Support for this research was provided by grants from the US National Science Foundation (BSR-9119867), the German Science Foundation (Me1725/5-1), and the University of Konstanz to A.M. Additional financial support was received from the Vern Parish Fund (to J.S.) and the US National Science Foundation (postdoctoral grant INT-00022130 to T.H.).

\section{References}

Anderson, S.A., Bankier, T., Barrell, B.G., de Bruijn, M.H.L., Coulson, A.R., Drouin, J., Eperon, I.C., Nierlich, D.P., Roe, B.A., Sanger, F., Schreier, P.H., Smith, A.J.H., Staden, R., Young, I.G., 1981. Sequence and organization of the human mitochondrial genome. Nature 290, $457-465$

Bermingham, E., Martin, A.P., 1998. Comparative mtDNA phylogeography of neotropical freshwater fishes: testing shared history to infer the evolutionary landscape of lower Central America. Mol. Ecol. 7, 499-517.

Briggs, J.C., 1994. The genesis of Central America: biology versus geophysics. Global Ecol. Biogeo. Lett. 4, 169-172.

Bussing, W.A., 1976. Geographic distribution of the San Juan ichthyofauna of Central America with remarks on its origin and ecology. In: Thorson, I.B. (Ed.), Investigations of the ichthyofauna of Nicaraguan 
Lakes, School Life Sciences. University of Nebraska, Lincoln, NE, pp. $157-175$.

Coates, A.G., Obando, J.A., 1996. The geological evolution of the Central American isthmus. In: Jackson, J., Budd, A.F., Coates, A.G. (Eds.), Evolution and Environment in Tropical America. University of Chicago Press, Chicago, IL, pp. 21-56.

Coney, P.J., 1982. Plate tectonic constraints on biogeographic connections between North and South America. Ann. Missouri Bot. Gard. 69, 432-443.

Costa, W.J.E.M., 1998. Phylogeny and classification of the Cyprinodontiformes (Euteleostei: Atherinomorpha): a reappraisal. In: Malabarba, L.R., Reis, R.E., Vari, R.P., Lucena, Z.M.S., Lucena, C.A.S. (Eds.), Phylogeny and Classification of Neotropical Fishes. EDIPUCRS, Porto Alegre, Brazil, pp. 537-560.

Ghedotti, M.J., 2000. Phylogenetic analysis and taxonomy of the poecilioid fishes (Teleostei: Cyprinodontiformes). Zool. J. Linn. Soc. $130,1-53$.

Hall, T., 1999. BioEdit: a user-friendly biological sequence alignment editor and analysis program for Windows 95/98/NT. Nucleic Acids Symp. Ser. 41, 95-98.

Hamilton, A., 2001. Phylogeny of Limia (Teleostei: Poeciliidae) based on NADH dehydrogenase subunit 2 (ND2) sequences. Mol. Phylogenet. Evol. 19, 277-289.

Hrbek, T., Larson, A., 1999. The evolution of diapause in the killifish family Rivulidae (Atherinomorpha, Cyprinodontiformes): a molecular phylogenetic and biogeographic perspective. Evolution 53, 1200-1216.

Hrbek, T., Meyer, A., 2003. Closing of the Tethys Sea and the phylogeny of Eurasian killifishes (Cyprinodontiformes: Cyprinodontidae). J. Evol. Biol. 16, 17-36.

Huelsenbeck, J.P., Ronquist, F.R., 2001. MRBAYES: Bayesian inference of phylogeny. Bioinformatics 17, 754-755.

Iturralde-Vinent, M.A., MacPhee, R.D.E., 1999. Paleogeography of the Caribbean region: Implications for Cenozoic biogeography. Bull. Am. Mus. Nat. Hist., 238.

Keigwin, L., 1982. Isotopic paleoceanography of the Caribbean and east Pacific: role of Panama uplift in late neogene time. Science 217, 350-353.

Kessing, B.D., Croon, B.H., Martin, A.P., McIntosh, C., McMillan, W.O., Palumbi, S.R., 1989. The simple fool's guide to PCR, version 1. Dept. of Zoology, Univ. of Hawaii, Honolulu.

Kishino, H., Hasegawa, M., 1989. Evaluation of the maximum likelihood estimate of the evolutionary tree topologies from DNA sequence data, and the branching order in Hominoidea. J. Mol. Evol. 29, 170-179.

Kumazawa, Y., Nishida, M., 1993. Sequence evolution of mitochondrial tRNA genes and deep-branch animal phylogenetics. J. Mol. Evol. 37, 380-398.

Langerhans, R.B., Layman, C.A., DeWitt, T.J., 2005. Male genital size reflects a tradeoff between attracting mates and avoiding predators in two live-bearing fish species. Proc. Natl. Acad. Sci. USA 102, 7618-7623.

Lucinda, P.H.F., 2003. Family Poeciliidae. In: Reis, R.E., Kullander, S.O., Ferraris, C.J. (Eds.), Check List of the Freshwater Fishes of South and Central America. EDIPUCRS, Porto Alegre, Brazil, pp. 555-581.

Lucinda, P.H.F., Reis, R.E., 2005. Systematics of the subfamily Poeciliinae Bonaparte (Cyprinodontiformes: Poeciliidae), with an emphasis on the tribe Cnesterodontini Hubbs. Neotrop. Ichthyol. 3, 1-60.

Lydeard, C., Wooten, M.C., Meyer, A., 1995. Cytochrome $b$ sequence variation and a molecular phylogeny of the live-bearing fish genus Gambusia (Cyprinodontiformes: Poeciliidae). Can. J. Zool. 73, 213-227.

Macey, J.R., Larson, A., Ananjeva, N.B., Papenfuss, T.J., 1997. Replication slippage may cause parallel evolution in the secondary structures of mitochondrial transfer RNAs. Mol. Biol. Evol. 14, 31-39.

Martin, A.P., 1999. Substitution rates of organelle and nuclear genes in sharks: implicating metabolic rate (again). Mol. Biol. Evol. 16, 996-1002.

Mateos, M., Sanjur, O.I., Vrijenhoek, R.C., 2002. Historical biogeography of the livebearing fish genus Poeciliopsis (Poeciliidae: Cyprinodontiformes). Evolution 56, 972-984.
Meyer, A., 1993. Evolution of mitochondrial DNA in fishes. In: Hochachka, P.W., Mommsen, T.P. (Eds.), Molecular Biology Frontiers: Biochemistry and Molecular Biology of Fishes, vol. 2. Elsevier, Amsterdam, Holland.

Meyer, A., Lydeard, C., 1993. The evolution of copulatory organs, internal fertilization, placentae and viviparity in killifishes (Cyprinodontiformes) inferred from a DNA phylogeny of the tyrosine kinase gene $X$-src. Proc. R. Soc. London B. 254, 153-162.

Meyer, A., Morrissey, J.M., Schartl, M., 1994. Recurrent origin of a sexually selected trait in Xiphophorus fishes inferred from a molecular phylogeny. Nature 368, 539-542.

Meyer, A., Salzburger, W., Schartl, M., 2006. Hybrid origin of a swordtail species (Teleostei: Xiphophorus clemenciae) driven by sexual selection. Mol. Ecol. 15, 721-730.

Miller, R.R., 1966. Geographic distribution of Central American freshwater fishes. Copeia 1966, 773-802.

Mojica, C.L., Meyer, A., Barlow, G.W., 1997. Phylogenetic relationships of species of the genus Brachyrhaphis (Poecilidae) inferred from partial mitochondrial DNA sequences. Copeia 1997, 298-305.

Myers, G.S., 1966. Derivation of the freshwater fish fauna of Central America. Copeia 1966, 766-773.

Ortí, G., Meyer, A., 1997. The radiation of characiform fishes and the limits of resolution of mitochondrial ribosomal DNA sequences. Syst. Biol. 46, 75-100.

Parenti, L.R., 1981. A phylogenetic and biogeographic analysis of cyprinodontiform fishes (Teleostei, Atherinomorpha). Bull. Am. Mus. Nat. Hist. 168, 335-557.

Parenti, L.R., Rauchenberger, M., 1989. Systematic overview of the poeciliines. In: Meffe, G.K., Snelson, F.F., Jr.Jr. (Eds.), Ecology and Evolution of Livebearing Fishes (Poeciliidae). Prentice Hall, Jersey City, NJ, pp. 3-12.

Perdices, A., Bermingham, E., Montilla, A., Doadrio, I., 2002. Evolutionary history of the genus Rhamdia (Teleostei: Pimelodidae) in Central America. Mol. Phylogenet. Evol. 25, 172-189.

Posada, D., Crandall, K.A., 1998. MODELTEST: testing the model of DNA substitution. Bioinformatics 14, 817-818.

Ptacek, M.B., Breden, F., 1998. Phylogenetic relationships among the mollies (Poeciliidae: Poecilia: Mollienesia group) based on mitochondrial DNA sequences. J. Fish Biol. 53, 64-81.

Rannala, B., Yang, Z., 1996. Probability distribution of molecular evolutionary trees: a new method of phylogenetic inference. J. Mol. Evol. 43, 304-311.

Rauchenberger, M., 1989. Systematics and biogeography of the genus Gambusia (Cyprinodontiformes: Poeciliidae). Am. Mus. Novitates 2951, 1-74.

Rauchenberger, M., Kallman, K.D., Morizot, D.C., 1990. Monophyly and geography of the Río Pánuco Basin swordtails (genus Xiphophorus) with description of four new species. Am. Mus. Novitates 2975, $1-41$.

Reznick, D.N., Miles, D.B., 1989. A review of life history patterns in poeciliid fishes. In: Meffe, G.K., Snelson, F.F., Jr.Jr. (Eds.), Ecology and Evolution of Livebearing Fishes (Poeciliidae). Prentice Hall, Jersey City, NJ, pp. 125-149.

Reznick, D.N., Mateos, M., Springer, M.S., 2002. Independent origins and rapid evolution of the placenta in the fish genus Poeciliopsis. Science 298, 1018-1020.

Rodriguez, C.M., 1997. Phylogenetic analysis of the tribe Poeciliini (Cyprinodontiformes: Poeciliidae). Copeia 1997, 663-679.

Rodríguez, F.J., Oliver, J.L., Marín, A., Medina, J.R., 1990. The general stochastic model of nucleotide substitution. J. Theor. Biol. 142, 485-501.

Rosen, D.E., 1964. The relationships and taxonomic position of the halfbeaks, killifishes, silversides, and their relatives. Bull. Am. Mus. Nat. Hist. 127, 217-268.

Rosen, D.E., 1967. New poeciliid fishes from Guatemala, with comments on the origins of some South and Central American forms. Am. Mus. Novitates 2303, 1-15.

Rosen, D.E., 1975. A vicariance model of Caribbean biogeography. Syst. Zool. 24, 431-464. 
Rosen, D.E., 1979. Fishes from the uplands and intermontane basins of Guatemala: revisionary studies and comparative geography. Bull. Am. Mus. Nat. Hist. 162, 267-376.

Rosen, D.E., Bailey, R.M., 1963. The poeciliid fishes (Cyprinodontiformes), their structure, zoogeography, and systematics. Bull. Am. Mus. Nat. Hist. 126, 1-176.

Sanderson, M.J., 2002. Estimating absolute rates of molecular evolution and divergence times: a penalized likelihood approach. Mol. Biol. Evol. 19, 101-109.

Savage, J.M., 1966. The origins and history of the Central American herpetofauna. Copeia 1966, 719-766.

Savage, J.M., 1974. The isthmian link and the evolution of neotropical mammals. Nat. Hist. Mus. Los Angeles Co. Contrib. Sci. 260, $1-51$.

Savage, J.M., 1982. The enigma of the Central American herpetofauna: dispersals or vicariance? Ann. Missouri Bot. Gard. 69, 464-547.
Shimodaira, H., Hasegawa, M., 1999. Multiple comparisons of loglikelihoods with applications to phylogenetic inference. Mol. Biol. Evol. 16, 1114-1116.

Swofford, D.L., 2002. PAUP*. Phylogenetic Analysis Using Parsimony (* and Other Methods), Beta Version 4b10. Sinauer Associates, Sunderland, MA

Thibault, R.E., Schultz, R.J., 1978. Reproductive adaptations among viviparous fishes (Cyprinodontiformes: Poeciliidae). Evolution 32, 320-333.

Turner, C.L., 1940. Pseudoamnion, pseudochorion, and follicular pseudoplacenta in poeciliid fishes. J. Morphol. 67, 59-89.

Waters, J.M., López, J.A., Wallis, G.P., 2000. Molecular phylogenetics and biogeography of galaxiid fishes (Osteichthyes: Galaxiidae): dispersal, vicariance, and the position of Lepidogalaxias salamandroides. Syst. Biol. 49, 777-795.

Zhang, D.-X., Hewitt, G.M., 1996. Nuclear integrations: challenges for mitochondrial DNA markers. Trends Ecol. Evol. 11, 247-251. 